\title{
Extraction of Zinc Chloride by Trilaurylammonium Chloride and Trilaurylamine in Xylene
}

\author{
DAVID DYRSSEN and MARIA DE JESUS TAVARES* \\ Department of Analytical Chemistry,** University of Göteborg, Gibraltargatan 5 A, \\ Göteborg S, and Department of Inorganic Chemistry, Royal Institute of \\ Technology (KTH), Stockholm, 70, Sweden
}

\begin{abstract}
Distribution experiments with ${ }^{\circ} \mathrm{Zn}$ have shown that the distribution ratio of $\mathrm{Zn}$ (II) between TLA. $\mathrm{HCl}$ (trilaurylammonium chloride) in 0 -xylene and $\mathrm{HCl}$ is proportional to [TLA-HCl$]^{2}$ org,tot regardless of whether TLA.HCl is in the monomeric form or in an associated state. The distribution ratio between TLA (basic form) in 0 -xylene and $3 \mathrm{M} \mathrm{LiCl}$ is proportional to [TLA] $]_{\text {org. The distribution curves }}$ (log $\mathrm{D} v s . \log \left[\mathrm{Cl}^{-}\right]$) for $0.5 \%$ and $2 \%$ TLA.HCl in 0 -xylene show a maximum for $3 \mathrm{M} \mathrm{HCl}$ or $\mathrm{LiCl}$, indicating that the complex formation between $\mathrm{Zn}^{2}+$ and $\mathrm{Cl}^{-}$may be weaker than previous measurements have shown. Loading experiments with $2 \%$ TLA.HCl and 3 M (H, Zn) Cl give additional proof that zinc(II) is present in the organic phase as $\mathrm{ZnCl}_{4}{ }^{2-}$.
\end{abstract}

\section{AGGREGATION OF TRILAURYLAMMONIUM CHLORIDE IN 0 -XYLENE}

Högfeldt and Tavares ${ }^{1}$ have recently investigated the equilibria between Atrilaurylamine (TLA or B) in $o$-xylene and hydrochloric acid at $25^{\circ} \mathrm{C}$ for an aqueous phase with constant chloride concentration, i.e. $1 \mathrm{M}(\mathrm{H}, \mathrm{Li}) \mathrm{Cl}$. From this study the following equilibria have been computed:2

$\mathrm{H}^{+}(\mathrm{aq})+\mathrm{Cl}^{-}(\mathrm{aq})+\mathrm{B}$ (org) $\rightleftharpoons \mathrm{BHCl}$ (org); $\log K_{\mathrm{a}}=3.328 \pm 0.008$

$3 \mathrm{BHCl}$ (org) $\rightleftharpoons(\mathrm{BHCl})_{3}$ (org); $\log \beta_{3}=3.096 \pm 0.024$

$48 \mathrm{BHCl}$ (org) $\rightleftharpoons(\mathrm{BHCl})_{48}\left(\right.$ org); $\log \beta_{48}=69.27 \pm 0.12$

Note that our $K_{\mathrm{a}}=k_{1,1}$ and our $\beta_{n}=k_{n, n} / k_{1,1}{ }^{n}$ as used in Refs. 1,2.

The organic phase should thus contain a monomer, a trimer and a rather large polymer, depending on the total concentration of $\mathrm{BHCl}$ in the o-xylene

* Present address: Laboratório de Física e Engenharia Nucleares, Sacavém, Portugal.

** Reprints and distribution data are available from this department. 
Fig. 1. The concentration of TLA.HCl monomer as a function of the total concentration of TLA. HCl in $o$-xylene when $C_{\mathrm{B}}=[\mathrm{BHCl}]_{\text {org }}+3 \beta_{3}[\mathrm{BHCl}]^{3}$ org + $48 \beta_{48}[B H C l]_{o r g}{ }^{48}$. The dashed curve rep. resents the case when the polymer $(\mathrm{BHCl})_{48}$ is neglected and the limiting value of $\log [\mathrm{BHCl}]_{\text {org }}=-1.42$ is set by the aggregation constant given by Högfeldt. ${ }^{2}$

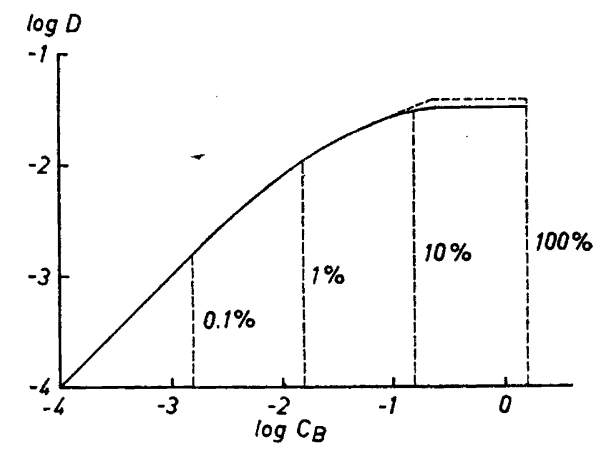

phase $\left(C_{\mathrm{B}}\right)$. Computer calculations have indicated a best fit with a polymer with $n=48 \mathrm{BHCl}$ molecules, but other values of $n$ are also in good agreement with the experimental data.

The values of $\beta_{3}$ and $\beta_{48}$ are sufficient to calculate the concentration of the monomer, $[\mathrm{BHCl}]_{\text {org }}$, as a function of the total concentration of $\mathrm{BHCl}$ in the organic phase

$$
C_{\mathrm{B}}=[\mathrm{BHCl}]_{\mathrm{org}}+3 \beta_{3}[\mathrm{BHCl}]^{3}{ }_{\mathrm{org}}+48 \beta_{48}[\mathrm{BHCl}]^{48}{ }_{\mathrm{org}}
$$

Fig. 1 shows that $C_{\mathrm{B}} \approx[\mathrm{BHCl}]_{\text {org }}$ at low $C_{\mathrm{B}}(>0.1 \%)$ and that $\log [\mathrm{BHCl}]_{\text {org }}$ approaches -1.48 at high $C_{\mathrm{B}}$ indicating that above $\log C_{\mathrm{B}}=-0.8(>10 \%)$ TLA.HCl behaves as a separate phase. In the presence of such a third phase the concentration of all species of $\mathrm{BHCl}$ in the diluent (o-xylene) should be constant.

In his treatment of the two-phase titration data ${ }^{1}$ Högfeldt $^{2}$ has shown, that when large aggregates are formed, they can be treated as a separate phase with a constant product $\left[\mathrm{H}^{+}\right]\left[\mathrm{Cl}^{-}\right][\mathrm{B}]_{\text {org }}=10^{-4.75}$, i.e. $[\mathrm{BHCl}]_{\text {org }}=10^{-4.75+3.33}$ $=10^{-1.42}$ using $K_{\mathrm{a}}=10^{3.33}$. The question then arises whether the polymer $(\mathrm{BHCl})_{48}$ belongs to the diluent or to the aggregated third phase. Fig. 1 also shows $\log [\mathrm{BHCl}]_{\text {org }}$ as a function of $\log C_{\mathrm{B}}=\log \left([\mathrm{BHCl}]_{\text {org }}+3 \beta_{3}[\mathrm{BHCl}]_{\text {org }}\right)$ (dashed curve). The curve should show a discontinuity at log $[\mathrm{BHCl}]_{\text {org }}=$ $\sim 1.42$ (16\% TLA.HCl) when the third phase is formed. Since no such discontinuity is discernible in two-phase titration experiments, a better fit with the experimental data is obtained by taking into account the presence of a higher polymer in between the monomer and trimer and the "point" of aggregation. The general experience is that the position of this "point" depends on stirring conditions, content of acid, water and metal salts, temperature etc., and it is thus not always observed even if crystalline products do sometimes appear. Fig. 1 shows, however, that below $7 \%$ TLA.HCl in $o$-xylene aggregation (third phase formation) can be neglected together with the formation of higher polymers such as $(\mathrm{BHCl})_{48}$. 


\section{SCOPE OF INVESTIGATION AND SOME PREVIOUS WORK}

The intention of this work was to use the recent information of the aggregation of a "liquid anion exchanger" in a distribution study of zinc(II). A similar distribution study of zinc(II) using $10 \%$ methyldioctylammonium chloride in trichlorethylene has previously been carried out by Schindewolf. ${ }^{3}$ Nothing is, however, known about the polymerization of $\mathbf{R}_{3} \mathrm{NHCl}$ in this system, which restricts the treatment of the distribution data to some extent.

We also wished to make "loading" studies similar to those made on Dowex-1 by Horne, Holm and Meyers ${ }^{4}$ to ascertain whether or not $\mathrm{ZnCl}_{4}{ }^{2-}$ is the dominant species in the organic phase at high concentrations of $\mathrm{ZnCl}_{2}$. According to investigations of the complex formation between $\mathrm{Zn}^{2+}$ and $\mathrm{Cl}^{-}$by Shchukarev, Lilich and Latysheva ${ }^{5}$ as well as Short and Morris ${ }^{6}$ and Biedermann $^{7}$ (who has obtained $K\left(\mathrm{ZnCl}^{3-}+\mathrm{Cl}^{-} \rightleftharpoons \mathrm{ZnCl}_{4}{ }^{2-}\right.$ ) $=1.8$ in $5 \mathrm{M} \mathrm{LiCl}$ ) the saturated complex in aqueous solutions is $\mathrm{ZnCl}_{4}{ }^{2-}$. The same conclusions as to the maximum ligand number have been confirmed by Raman studies ${ }^{8}$ of $\mathrm{ZnCl}_{2}$ and $\mathrm{LiCl}$ in methanol. Raman spectra ${ }^{6}$ suggest a tetrahedral configuration of $\mathrm{ZnCl}_{4}{ }^{2-}$ in aqueous solutions and tributylphosphate extracts, but other Raman studies ${ }^{10}$ indicate a planar structure. Furthermore, $\mathrm{ZnCl}_{4}{ }^{2-}$ seems to be a stable unit 11,12 with a tetrahedral configuration in several crystalline salts of the type $\mathrm{M}_{2} \mathrm{ZnCl}_{4}$. In addition there is also some evidence ${ }^{9}$ that in aqueous solutions the $\mathrm{Zn}^{2+}$ ion coordinates, six molecules of water, and that the third complex is $\mathrm{ZnCl}_{3}\left(\mathrm{H}_{2} \mathrm{O}\right)_{2}{ }^{-}$with a trigonal bipyramidal structure.

The distribution of zinc(II) between solid anion exchangers (e.g. Dowex-1) and chloride solutions has been studied by many workers. The most recent study has been published by Marcus and Maydan. ${ }^{13}$ By correcting the distribution data for invasion in the resin of the electrolyte in the aqueous phase, they concluded that $\mathrm{ZnCl}_{4}{ }^{2-}$ was the main species in the anion exchange resin phase as well as the saturated species in the aqueous phase. No invasion of $\mathrm{LiCl}$ could be detected in the o-xylene-TLA.HCl phase (flame test for lithium; compare with Ref. 14). At $\mathrm{HCl}$ concentrations greater that $3 \mathrm{M} \mathrm{HCl}$ dissolves in the organic phase. 1

Equilibrium (1) demostrates that $\mathrm{BHCl}$ can be hydrolysed at low concentrations of $\mathrm{HCl}$ in the aqueous phase. As it has been shown ${ }^{15,16}$ that $\mathrm{Cd}(\mathrm{OH})_{2}$ and $\mathrm{Zn}(\mathrm{OH})_{2}$ can be extracted by the basic form of Amberlite LA-1, the extraction of $\mathrm{ZnCl}_{2}$ by $\mathrm{R}_{3} \mathrm{~N}$ in $o$-xylene from $3 \mathrm{M} \mathrm{LiCl}$ was also studied. The formation constants of $\mathrm{ZnOH}^{+}$and $\mathrm{Zn}(\mathrm{OH})_{4}^{2-}$ in $3 \mathrm{M} \mathrm{Na}(\mathrm{Cl}, \mathrm{OH})$ have been determined by Schorsch ${ }^{17}$ to be as follows:

$$
\begin{aligned}
& \mathrm{Zn}^{2+}+\mathrm{H}_{2} \mathrm{O} \rightleftharpoons \mathrm{ZnOH}{ }^{+}+\mathrm{H}^{+} ; \log ^{*} \beta_{1}=-9.25 \\
& \mathrm{Zn}^{2+}+4 \mathrm{H}_{2} \mathrm{O} \rightleftharpoons \mathrm{Zn}(\mathrm{OH})_{4}{ }^{2-}+4 \mathrm{H}^{+} ; \log ^{*} \beta_{4}=-42.96
\end{aligned}
$$

By the addition of small amounts of $\mathrm{HCl}$ to the $3 \mathrm{M} \mathrm{LiCl}$ phase we were able to keep the $\mathrm{pH}$ close to 6 and thus avoid the formation of $\mathrm{Zn}(\mathrm{OH})_{2}$ as well as of $\mathrm{BHCl}$.

\section{EXPERIMENTAL}

Reagents. The hydrochloric acid (Merck p.a.) was used without further purification. Lithium chloride (Mallinckrodt A.R. grade) was purified by double recrystallisation and 
was then dissolved in doubly-distilled water. The dilute standard solutions were prepared from the concentrated stock solutions and were analysed for chloride by the Volhard volumetric method.

Zinc chloride (Merck p.a. $\mathrm{ZnCl}_{2}$ ) was dried in an oven at $150^{\circ} \mathrm{C}$ and stored in a desiccator over silica gel.

Trilaurylamine, containing no more than $1 \% \mathrm{~N}$ as primary and secondary amines, was supplied by Rhone-Poulenc and used without purification.

Analysis of the diluent, o-xylene (Fluka, reagent grade) by vapour phase chromatography showed the presence of $99 \% 0$-xylene, $0.7 \% \mathrm{~m}$ - and $p$-xylene and $0.07 \%$ ethylbenzene.

Freshly prepared amine solutions were used, which were stored in the dark to minimise decomposition when not in use.

Radioactive ${ }^{65} \mathrm{Zn}$ was supplied as an aqueous solution of zinc chloride by the Radiochemical Centre, Amersham, England. The concentration of $\mathrm{Zn}$ in this solution was 27.8 $\mathrm{mg}$ per $3.2 \mathrm{ml}(0.133 \mathrm{M})$ and the total activity of ${ }^{65} \mathrm{Zn}$ was $10.1 \mathrm{mC}$. The radiochemical purity was checked by "double extraction" as follows: $1 \%$ and $0.02 \%$ TLA.HCl in $0 \cdot x y l e n e$ was shaken with ${ }^{\circ 5} \mathrm{Zn}$ in $3 \mathrm{M} \mathrm{HCl}$. The organic layer was then shaken with inactive $3 \mathrm{M}$ HCl. The measured $\log D$ values agreed to within $0.015 \log$ units. The initial solution was diluted with either $\mathrm{HCl}$ or $\mathrm{LiCl}$ to solutions of known conentrations of $\mathrm{HCl}$ and $\mathrm{LiCl}$, the final zinc concentration being either $0.0000133 \mathrm{M}$ or $0.0000266 \mathrm{M}$. Practically no activity was lost in these experiments.

Distribution measurements. All the experiments were performed in a thermostated room at $25.0 \pm 0.3^{\circ} \mathrm{C}$.

In $50 \mathrm{ml}$ glass stoppered tubes equal volumes $(5$ or $10 \mathrm{ml}$ of cach) of the organic and the aqueous phases were equilibrated by means of a mechanical Microid flask shaker (Griffin and Tatlock Ltd, England). It was found that agitation for 30 min with the Microid flask shaker was sufficient to attain equilibrium, whereas agitation by tilting the tubes with a mechanical rotator for $3 \mathrm{~h}$ was not, however, sufficient for the attainment of equilibrium. After equilibration the tubes were centrifuged and $4.00 \mathrm{ml}$ aliquots of each phase were removed carefully, to avoid contamination of one phase by the other, by means of a pipette and transferred to $5 \mathrm{ml}$ polyethylene counting tubes. These tubes were counted using a well-type, Tracerlab-SC-57 scintillation counter. The distribution ratio $D$ for ${ }^{\circ} \mathrm{Zn}$ (organic/aqueous phase) was thus the ratio of the counts/min (corrected for background) in each phase.

The hydrochloric acid concentration in the initial aqueous phase of each sample was known. In some cases, however, where the concentration of the acid in the initial aqueous phase was less than $1 \mathrm{M}$ after equilibration and centrifugation, aliquots of both phases were analysed for $\mathrm{Cl}^{-}$.

In all the cases but the one represented in Fig. 4 the organic phase containing TLA was shaken four times with half of its volume of $1 \mathrm{M} \mathrm{HCl}$ in order to convert TLA to TLA.HCl before the metal extraction experiments. After agitation the two phases were allowed to settle in the dark. After phase separation, the organic solutions were filtered in order to remove possible suspended aqueous drops.

\section{RESULTS AND DISCUSSION}

$D$ as a function of the concentration of $B H C l$. Two sets of data are shown in Fig. 2. The upper set represents experiments with $3 \mathrm{M} \mathrm{HCl}$, the lower experiments with $0.5 \mathrm{M} \mathrm{HCl}$. They fit fairly well to straight lines of gradient 2 . At constant chloride concentration in the aqueous phase the ratios between the different chloride complexes of zinc(II) are constant, which can be seen from eqn. (7). The expression for $D$ will then depend on how many BHCl react with $\mathrm{ZnCl}_{2}$ according to eqns. (6) and (8).

$$
D=\frac{\left[\left(\mathrm{BHCl}_{\mathbf{m}} \mathrm{ZnCl}_{2}\right]_{\text {org }}\right.}{\left[\mathrm{Zn}^{2+}\right]+\left[\mathrm{ZnCl}^{+}\right]+\left[\mathrm{ZnCl}_{2}\right]+\left[\mathrm{ZnCl}_{3}^{-}\right]+\left[\mathrm{ZnCl}_{4^{2-}}{ }^{-}\right]}
$$

Acta Chem. Scand. 20 (1966) No. 8 


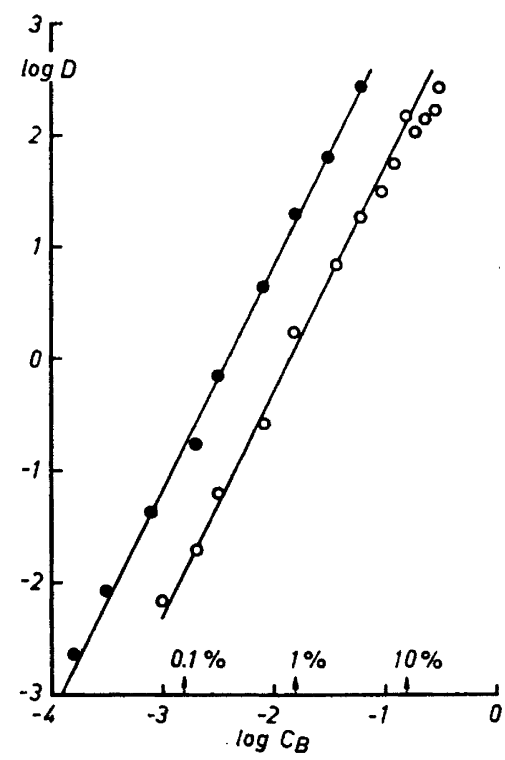

Fig. 2. Distribution of ${ }^{65} \mathrm{Zn}$ between $o-$ xylene and $\mathrm{HCl}$ as a function of the total concentration of TLA.HCl in the organic phase. The open circles represent $0.5 \mathrm{M}$ $\mathrm{HCl}$ and the filled circles $3 \mathrm{M} \mathrm{HCl}$. The lines are drawn with a slope of 2 .

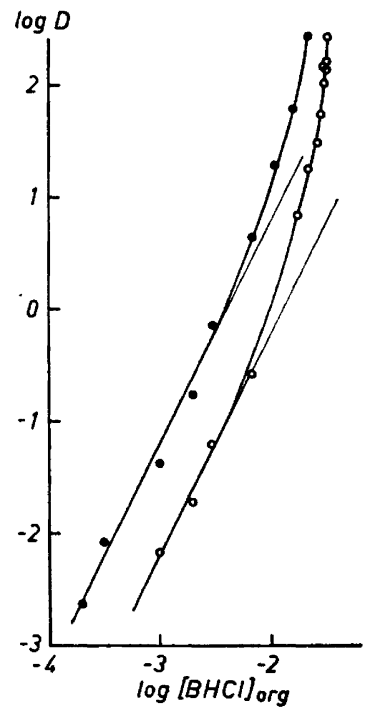

Fig. 3. Distribution of ${ }^{65} \mathrm{Zn}$ between solutions of TLA. $\mathrm{HCl}$ in $o$-xylene and $0.5 \mathrm{M}$ $\mathrm{HCl}$ (open circles) or $3 \mathrm{M} \mathrm{HCl}$ (filled circles). The data are plotted as $\log D$ against $\log$ $[\mathrm{BHCl}]_{\text {org, }}$ the conc. of the monomer of TLA.HCl in the organic phase. The straight part of the curves are drawn with a slope of 2.

or

$$
D=\frac{K_{m}[\mathrm{BHCl}]_{\mathrm{org}}{ }^{m} \beta_{2}\left[\mathrm{Cl}^{-}\right]^{2}}{1+\beta_{1}\left[\mathrm{Cl}^{-}\right]+\beta_{2}\left[\mathrm{Cl}^{-}\right]^{2}+\beta_{3}\left[\mathrm{Cl}^{-}\right]^{3}+\beta_{4}\left[\mathrm{Cl}^{-}\right]^{4}}
$$

where

$$
\left[\mathrm{ZnCl}_{n}\right]=\beta_{n}\left[\mathrm{Zn}^{2+}\right]\left[\mathrm{Cl}^{-}\right]^{n}
$$

and

$$
\left[(\mathrm{BHCl})_{m} \mathrm{ZnCl}_{2}\right]_{\text {org }}=K_{m}\left[\mathrm{ZnCl}_{2}\right][\mathrm{BHCl}]_{\text {org }}{ }^{m}=K_{m}[\mathrm{BHCl}]_{\mathrm{org}}{ }^{m} \beta_{2}\left[\mathrm{Zn}^{2+}\right]\left[\mathrm{Cl}^{-}\right]^{2}
$$

Thus if $\log D$ is plotted against $\log [\mathrm{BHCl}]_{\text {org }}$ at constant $\left[\mathrm{Cl}^{-}\right]$the slope should give $m$. Fig. 3 shows that $m=2$ at low concentrations of $\mathrm{BHCl}\left(\mathrm{C}_{\mathrm{B}} \leq\right.$ $0.004 \mathrm{M}$ ) where $\mathrm{BHCl}$ is mainly in the monomeric form. Fig. 3 and Fig. 1 also show that the slope of the curve $\log D$ vs. $\log [\mathrm{BHCl}]_{\text {org }}$ increases when $\mathrm{BHCl}$ polymerises. The straight lines in Fig. 2 where $\log D$ is plotted against $\log C_{\mathrm{B}}$ may imply that monomeric and polymeric $\mathrm{BHCl}$ react equally easily with $\mathrm{ZnCl}_{2}$. The slope of 2 agrees very well with tendency of $\mathrm{Zn}^{2-}$ to form $\mathrm{ZnCl}_{4}{ }^{2-}$. The organic phase containing $\mathrm{BHCl}$ can be assumed to be a favorable medium for the formation of the saturated complex.

Even if slopes with small whole number gradient are very often obtained when $\log D$ for the distribution of a metal ion is plotted against the logarithm 
of the total concentration of an alkylammonium salt, there are many exceptions, and the slope alone should not be taken as a proof of the formation of a certain metal complex. The number of $\mathrm{BHX}$ per $\mathrm{MX}_{\mathrm{N}}$ can only be obtained if $\log D$ is plotted against $\log [\mathrm{BHX}]_{\text {org }}$, the concentration of the monomeric form.

The value of $K_{2}$ can be determined from Fig. 3 using the values of $\beta_{n}$ given in the literature. The values of $\beta_{2}\left[\mathrm{Cl}^{-}\right]^{2}\left(1+\beta_{1}\left[\mathrm{Cl}^{-}\right]+\beta_{2}\left[\mathrm{Cl}^{-}\right]^{2}+\beta_{3}\left[\mathrm{Cl}^{-}\right]^{3}+\right.$ $\left.\beta_{4}\left[\mathrm{Cl}^{-}\right]^{4}\right)^{-1}$ in $0.5 \mathrm{M} \mathrm{HCl}$ are as follows:

Shchukarev, Lilich and Latysheva: ${ }^{5} 0.142$

Short and Morris: ${ }^{6} 0.169$

Marcus and Maydan: $:^{13} 0.261$

Kivalo and Luoto: ${ }^{18} 0.171$

The mean value is $10^{-0.75}$ and from $\log D=\log K_{2}+2 \log [\mathrm{BHCl}]_{\text {org }}-$ -0.73 we obtain $\log K_{2}=4.53$, where $K_{2}$ represents the stability constant for the following equilibrium:

$\mathrm{ZnCl}_{2}(0.5 \mathrm{M} \mathrm{HCl})+2 \mathrm{BHCl}(o-x y l e n e) \rightleftharpoons(\mathrm{BH})_{2} \mathrm{ZnCl}_{4}$ (o-xylene)

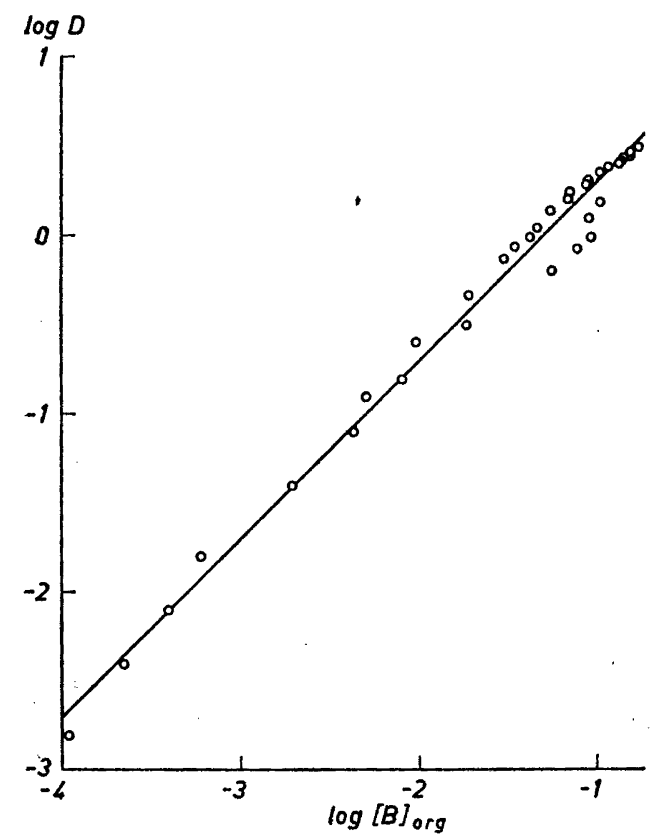

Fig. 4. Distribution of ${ }^{\circ} \mathrm{Zn}$ between solu. tions of TLA (base form) in 0 -xylene and $3 \mathrm{M}$ LiCl. The data are plotted as $\log D$ against $\log [\mathrm{B}]_{\text {org. }}$. The straight line is drawn with a slope of 1 .

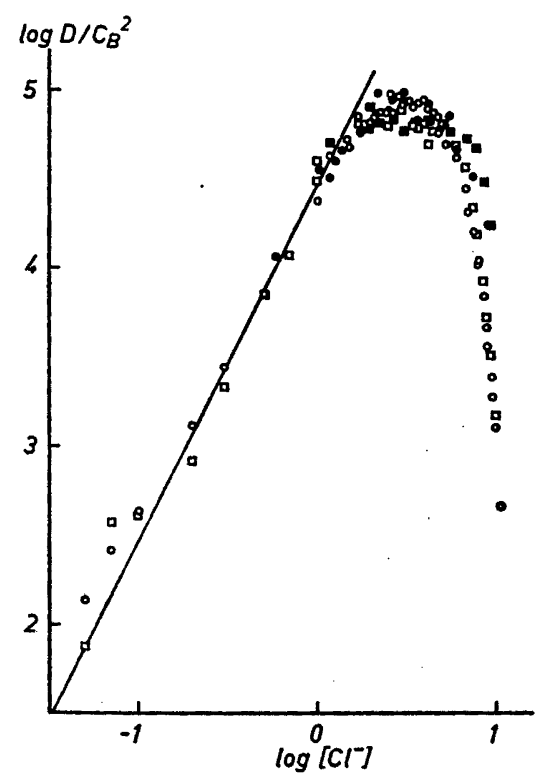

Fig. 5. Distribution of ${ }^{65} \mathrm{Zn}$ between TLA. $\mathrm{HCl}$ in $\mathrm{o}$-xylene and $\mathrm{HCl}$ (open symbols) or $\mathrm{LiCl}$ (filled symbols). Squares represent $0.5 \%$ TLA.HCl and circles represent $2 \%$ TLA.HCl. The data are plotted as $\log D / C_{\mathrm{B}}{ }^{2}$ against $\log \left[\mathrm{Cl}^{-}\right]$. The thin straight line is drawn with a slope of 2 .

Acta Chem. Scand. 20 (1966) No. 8 
$D$ as a function of the concentration of $B$. Fig. 4 shows that the distribution data for 0 -xylene-TLA and $3 \mathrm{M} \mathrm{LiCl}$ fit a straight line with a slope of 1 when plotted as $\log D$ vs. $\log [\mathrm{B}]_{\text {org. }}$. As the two-phase titration data ${ }^{1}$ showed that $\mathrm{B}$ has practically no tendency to associate with $\mathrm{B}$ or $\mathrm{BHCl}$, which would probably not be the case with primary and secondary amines where hydrogen bonding can occur, we may explain the straight line by the following equilibrium (equilibrium constant $K$ )

$$
\mathrm{ZnCl}_{2}(3 \mathrm{M} \mathrm{LiCl})+\mathrm{B} \text { (o-xylene) } \rightleftharpoons \mathrm{ZnBCl}_{2} \text { (o-xylene) }
$$

the expression for the net distribution ratio being

or

$$
D=\frac{\left[\mathrm{ZnBCl}_{2}\right]_{\text {org }}}{\left[\mathrm{Zn}^{2+}\right]+\left[\mathrm{ZnCl}^{+}\right]+\left[\mathrm{ZnCl}_{2}\right]+\left[\mathrm{ZnCl}_{3}{ }^{-}\right]+\left[\mathrm{ZnCl}_{4}^{2-}\right]}
$$

$$
D=\frac{K[\mathrm{~B}]_{\text {org }} \beta_{2}\left[\mathrm{Cl}^{-}\right]^{2}}{1+\beta_{1}\left[\mathrm{Cl}^{-}\right]+\beta_{2}\left[\mathrm{Cl}^{-}\right]^{2}+\beta_{3}\left[\mathrm{Cl}^{-}\right]^{3}+\beta_{4}\left[\mathrm{Cl}^{-}\right]^{4}}
$$

As above we may use the values of $\beta_{n}$ found by others in order to calculate $\beta_{2}\left[\mathrm{Cl}^{-}\right]^{2}\left(1+\beta_{1}\left[\mathrm{Cl}^{-}\right]+\beta_{2}\left[\mathrm{Cl}^{-}\right]^{2}+\beta_{3}\left[\mathrm{Cl}^{-}\right]^{3}+\beta_{4}\left[\mathrm{Cl}^{-}\right]^{4}\right)^{-1}$ for $3 \mathrm{M} \mathrm{LiCl}$ and then calculate $K$.

Shchukarev, Lilich and Latysheva: ${ }^{5} 0.099$

Short and Morris: ${ }^{6} 0.150$

Marcus and Maydan:13 0.136

Kivalo and Luoto: ${ }^{18} 0.274$

The mean of the first three values is $10^{-0.78}$ and from $\log D=\log K+\log$ $[\mathrm{B}]_{\text {org }}-0.78$ we obtain $\log K=1.5$.

One might have expected the formation of a complex with two $\mathrm{B}\left(\mathrm{ZnB}_{2} \mathrm{Cl}_{2}\right)$, but owing to steric hindrance it is unlikely that two molecules of such a large tertiary amine as TLA can be bound to $\mathrm{ZnCl}_{2}$ to form a tetrahedral complex. Since we did not investigate the dependence on $\left[\mathrm{Cl}^{-}\right]$, our experiments do not, however, rule out the possibility of the tetrahedral zinc complexes $\mathrm{Li}^{+} \mathrm{ZnBCl}_{3}{ }^{-}$ and $\mathrm{ZnBCl}_{2} \mathrm{H}_{2} \mathrm{O}$.

$D$ as a function of the concentration of $\mathrm{Cl}^{-}$. Four sets of experiments were performed using two different concentrations of $\mathrm{BHCl}(0.5$ and $2 \%)$ and either $\mathrm{HCl}$ and $\mathrm{LiCl}$ in the aqueous phase in order to vary $\left(\mathrm{Cl}^{-}\right]$. The data are plotted as $\log D / C_{\mathrm{B}}{ }^{2}$ (cf. Fig. 2) against $\log \left[\mathrm{Cl}^{-}\right]$in Fig. 5. It may be seen from this figure that $D / C_{\mathrm{B}}{ }^{2}$ is practically the same for the two media up to $c a .6 \mathrm{M} \mathrm{Cl}^{-}$. Above $6 \mathrm{M}$ the distribution curve for $\mathrm{LiCl}$ lies above the curve for $\mathrm{HCl}$; the same effect has also been observed by Schindewolf ${ }^{3}$ in his investigation with $10 \%$ methyldioctylammonium chloride in trichloroethylene.

It is tempting to explain the distribution curve by the expression for $D$ given above (eqn. 6), as the first part of the distribution curve has a slope of 2 corresponding to

$$
D=K_{2}[\mathrm{BHCl}]^{2}{ }_{\text {org }} \beta_{2}\left[\mathrm{Cl}^{-}\right]^{2}
$$

Furthermore, the distribution curve shows a maximum as can be predicted from eqn (6). In Fig. 6 we have tried to fit the distribution data in Fig. 5 to a 


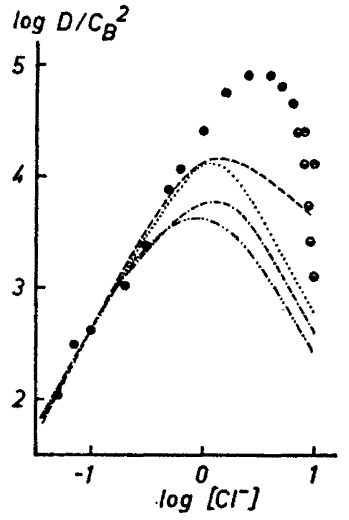

Fig. 6. Comparison between representative data from Fig. 5. and investigations of the complex formation between $\mathrm{Zn}^{2+}$ and $\mathrm{Cl}^{-}$ made by other authors. The shape of the distribution curve calculated from their data is fitted to the left part of the curve at lower $\left[\mathrm{Cl}^{-}\right]$. Symbols: -- Kivalo and Luoto, ${ }^{18}$........ Shchukarev, Lilich and Latysheva," .-...-. Short and Morris," ....--- Marcus and Maydan. ${ }^{13}$

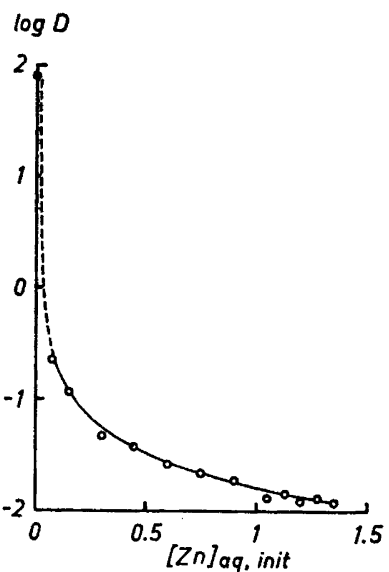

Fig. 7. Distribution of ${ }^{65} \mathrm{Zn}$ between $2 \%$ $(0.0312 \mathrm{M})$ TLA.HCl in $o$-xylene and $3 \mathrm{M}$ $(\mathrm{H}, \mathrm{Zn}) \mathrm{Cl}$ as a function of the initial molar concentration of $\mathrm{ZnCl}_{2}$ in the aqueous phase. The curve is calculated from $D=$ $0.0156 /\left([\mathrm{Zn}]_{\mathrm{aq}, \text { init }}-0.0156\right)$.

distribution curve whose form has been calculated (eqn. 6) using values of $\beta_{1}, \beta_{2}, \beta_{3}$, and $\beta_{4}$ found in the literature. None of the sets of constants given in Table 1 can, however, explain our distribution curve when fitted to the data for $0.1 \mathrm{M} \mathrm{Cl}^{-}$. According to previous $\beta_{n}$ values the distribution curve should have a maximum at $\left[\mathrm{Cl}^{-}\right] \approx 1 \mathrm{M}$ and not at $\left[\mathrm{Cl}^{-}\right] \approx 3 \mathrm{M}$.

The maximum shifts to approximately $8 \mathrm{M}$ if molar activities (1/2 log $\{\mathrm{LiCl}\}$ or $1 / 2 \log \{\mathrm{HCl}\})$ instead of molar concentrations are plotted along the abscissa. So we are either dealing with a salting out effect or the complex formation between $\mathrm{Zn}^{2+}$ and $\mathrm{Cl}^{-}$is considerably weaker than previous measurements have implied. The form of the curve calculated with the constants

Table 1. Stability constants $\beta_{n}$ (eqn. 7) for the complex formation between $\mathrm{Zn}^{2-}$ and $\mathrm{Cl}^{-}$.

\begin{tabular}{lccrrrrr}
\hline Authors & Temp. & $\begin{array}{c}\text { Ionic } \\
\text { strength } \\
\text { M }\end{array}$ & $\log \beta_{1}$ & $\log \beta_{2}$ & $\log \beta_{3}$ & $\log \beta_{4}$ \\
\hline Shehukarev, Lilich and & & & & & & \\
$\quad$ Latysheva $^{5}$ & 25 & 4.5 & -0.32 & -0.05 & -0.30 & -0.15 \\
Short and Morris $^{6}$ & 20 & 0.7 & 0.72 & 0.49 & -0.19 & 0.18 \\
Marcus and Maydan $^{13}$ & 25 & 0 & 0.43 & 0.61 & 0.53 & 0.20 \\
Kivalo and Luoto $^{18}$ & 25 & 2 & -0.49 & 0.02 & -0.07 &
\end{tabular}

Acta Chem. Scand. 20 (1966) No. 8 
of Shchukarev, Lilich and Latysheva ${ }^{5}$ would fit our distribution data up to $\left[\mathrm{Cl}^{-}\right] \approx 6 \mathrm{M}$ if shifted $0.40 \log \left[\mathrm{Cl}^{-}\right]$units to the right. This means that their values of $\log \beta_{n}$ should be reduced by $\mathrm{n} \times 0.40$.

Loading experiments. Fig. 7 shows how $\log D$ decreases when the zinc concentration is increased. At low zinc concentrations $\left(1.33 \times 10^{-5} \mathrm{M}\right) D$ $\sim 80$ for $3 \mathrm{M} \mathrm{HCl}$, so $98.8 \%$ should be extracted at equal phase volumes. If $\mathrm{Zn}$ (II) is, however, extracted in the form of $\mathrm{ZnCl}_{4}{ }^{2-}$, then [ $\left.\mathrm{Zn}\right]_{\text {org,tot }}$ cannot exceed $0.0156 \mathrm{M}$ (half of the concentration of $\mathrm{BHCl}$ in the organic phase). If the organic phase containing $\mathrm{BHCl}$ is loaded at $[\mathrm{Zn}]_{\mathrm{aq} \text {,init }}>0.0156 \mathrm{M}$, then $D=0.0156 /\left([\mathrm{Zn}]_{\mathrm{aq}, \text { init }}-0.0156\right)$. A curve based on this equation is drawn in Fig. 7, and fits the experimental data extremely well. This furnishes an additional proof that $\mathrm{Zn}$ (II) is extracted as a tetrachloro-complex.

Note added in proof. Articles by Scibona, Orlandini, and Danesi ${ }^{10}$ and by Lloyd ${ }^{20}$ on amine extractions of zinc chloride have appeared during the publication of this work. We have compared their results with ours in a paper ${ }^{21}$ read at the International Conference on Solvent Extraction Chemistry (ICSEC), which was has held in Göteborg, August 27 - September 1, 1966.

Acknowledgements. We wish to thank Professor Lars Gunnar Sillén and Dr. Erik Högfeldt for helpful discussions, Mrs. Susan Jagner, B. A. for revising the English text, and Mrs. Helle Persson, ing. for drawing the figures.

Our work on TLA has been supported by the Swedish Council for Atomic Research, the Swedish Atomic Energy Company, and Laboratório de Fisica e Engenharia Nucleares, Sacavém, Portugal.

\section{REFERENCES}

1. Högfeldt, E. and de Jesus Tavares, M. Trans. Roy. Inst. Technol. Stockholm, (1964) No. 228.

2. Högfeldt, E. Svensk Kem. Tidskr. 76 (1965) 290.

3. Schindewolf, V. Z. Elektrochem. 62 (1958) 335.

4. Horne, R. A., Holm, R. H. and Meyers, M. D. J. Phys. Chem. 61 (1957) 1655.

5. Shchukarev, S. A., Lilich, L. S. and Latysheva, V. A. Zh. Neorg. Khim. 1 (1956) 225.

6. Short, E. L. and Morris, D. F. C. J. Inorg. Nucl. Chem. 18 (1961) 192.

7. Biedermann, G. Private communication.

8. Kecki, Z. Spectrochim. Acta 18 (1962) 1165.

9. Morris, D. F. C., Short, E. L. and Waters, D. N. J. Inorg. Nucl. Chem. 25 (1963) 975.

10. Irish, D. E., McCarroll, B. and Young, T. F. J. Chem. Phys. 39 (1963) 3436.

11. Morosin, B. and Lingafelter, E. C. Acta Cryst. 12 (1959) 611.

12. Brehler, B. Z. Krist. 114 (1960) 66; 109 (1957) 68.

13. Marcus, Y. and Maydan, D. J. Phys. Chem. 67 (1963) 979.

14. Scibona, G., Danesi, P. R., Orlandini, F. and Coryell, C. D. J. Phys. Chem. 70 (1966) 141.

15. Dyrssen, D. and Lumme, P. Acta Chem. Scand. 16 (1962) 1785.

16. Sekine, T. Acta Chem. Scand. 19 (1965) 1526.

17. Schorsch, G. Thèses de l'université de Strasbourg DE 280 (1964).

18. Kivalo, P. and Luoto, R. Suomen Kemistilehti 30 B (1957) 163.

19. Scibona, G., Orlandini, F. and Danesi, P. R J. Inorg. Nucl. Chem. 18 (1966) 1313.

20. Lloyd, P. J. D. Proc. ICSEC, North-Holland 1967.

21. Dyrssen, D. and de Jesus Tavares, M. Proc. ICSEC, North-Holland 1967.

Received April 5, 1966. 